\title{
Các yếu tố ảnh hưởng đến thuê ngoài dịch vụ và tầm quan trọng của thuê ngoài dịch vụ đến các doanh nghiệp nhỏ và vừa tại Thành phố Cần Tho
}

\section{Factors influencing the outsourcing decisions and the importance of outsourcing on financial performance of SMEs in Can Tho City}

Đinh Công Thành ${ }^{1 *}$, Lê Tấn Nghiêm ${ }^{1}$

${ }^{1}$ Trường Đại học Cần Thơ, Việt Nam

*Tác giả liên hệ, Email: dcthanh@ctu.edu.vn

\begin{tabular}{|c|c|}
\hline THÔNG TIN & TÓM TẮT \\
\hline $\begin{array}{l}\text { DOI: 10.46223/HCMCOUJS. } \\
\text { econ.vi.13.3.521.2018 }\end{array}$ & $\begin{array}{l}\text { Nghiên cứu xác định các yếu tố tác động đến mức độ thuê } \\
\text { ngoài dịch vụ và sự tác động của mức độ thuê ngoài đến hiệu quả } \\
\text { tài chính của các doanh nghiệp nhỏ và vừa (DNNVV) tại thành }\end{array}$ \\
\hline Ngày nhận: 21/06/2018 & phố Cần Thơ. Dữ liệu thu thập là 153 DNNVV sử dụng dịch vụ \\
\hline Ngày nhận lại: 31/10/2018 & thuê ngoài. Nghiên cứu đã sử dụng công cụ kiểm định Cronbach's \\
\hline Duyệt đăng: 31/10/2018 & $\begin{array}{l}\text { Alpha, nhân tô khăng định (CFA) và mô hình câu trúc tuyên tính } \\
\text { (SEM). Kết quả cho thấy, việc thuê ngoài dịch vụ đã tác động tích } \\
\text { cực đến hiệu quả tài chính doanh nghiệp bao gồm: (1) tỷ suât lợi } \\
\text { nhuận trên tài sản - ROA, (2) tỷ suất lợi nhuận trên doanh thu - }\end{array}$ \\
\hline $\begin{array}{l}\text { Tù khóa: } \\
\text { dịch vụ thuê n } \\
\text { tài chính. ROA }\end{array}$ & $\begin{array}{l}\text { ROS và (3) tỷ suất lợi nhuận trên vốn chủ sở hữu - ROE. Trong } \\
\text { đó, sử dụng nguồn lực thuê ngoài tác động đáng kể nhất đến tỷ } \\
\text { suất ROA và ROE. }\end{array}$ \\
\hline
\end{tabular}
tài chính, ROA, ROE, ROS

Keywords:

outsourcing, financial performance, ROA, ROE, ROS

\section{ABSTRACT}

The present study aimed to examine factors that affect the outsourcing decisions, and the importance of outsourcing on the financial performance of SMEs in Can Tho city. The data was collected by interviewing 153 SMEs who used outsourcing. The research methodology included Cronbach's alpha test, Confirmatory factor analysis (CFA) and Structural equation modeling (SEM). The results showed that outsourcing services had a stronger impact on the financial performance of SMEs in Can Tho city including (1) the Return on Sales ratio - ROS, (2) the Return on Assets ratio - ROA and (3) the Return On common Equity ratio - ROE. Particularly, the use of outside resources had the strongest effect on ROA and ROE ratio. 


\section{Giới thiệu}

Thuê ngoài dịch vụ được hiểu là việc doanh nghiệp đi thuê một tổ chức/cá nhân cung ứng dịch vụ bên ngoài nhằm thực hiện một phần hay toàn bộ các phần công việc tại doanh nghiệp (Dong, Seongcheol, Changi, \& Ja, 2007). Thuê ngoài được xem là một công cụ quản lý giúp doanh nghiệp giảm chi phí (Gerald, Grace, \& Christina, 2013; Gilley, Greer, \& Rasheed, 2004), tăng lợi nhuận, giảm bớt tính cồng kềnh của bộ máy và đặc biệt là giúp tiết kiệm thời gian, chi phí trong quản trị (Gerald et al., 2013). Do đó, các doanh nghiệp trên thế giới đã ngày càng mạnh dạn sử dụng dịch vụ thuê ngoài, đặc biệt trong bối cảnh kinh tế khó khăn và cạnh tranh khốc liệt của các DNNVV. Theo đó, nhiều nghiên cứu đã khẳng định rằng giải pháp giúp doanh nghiệp có thể giải quyết những khó khăn đó là sử dụng dịch vụ thuê ngoài (Anders \& Björn, 2015; Hafeez \& Andersen, 2014).

Trong thời gian qua, mặc dù có sự phát triển về số lượng doanh nghiệp tại ĐBSCL nói chung và TP. Cần Thơ nói riêng, nhưng doanh nghiệp tại Cần Thơ chủ yếu là DNNVV (chiếm $98,31 \%$ ), trình độ quản lý thấp, thiếu vốn, đầu ra không ổn định, nhất là chi phí hoạt động tăng cao, khó cạnh tranh với các doanh nghiệp khác trong và ngoài nước (Dinh \& Le, 2017). Do đó, việc định hướng cho các DNNVV ở Cần Thơ sử dụng hiệu quả dịch vụ thuê ngoài để phát huy đến mức cao nhất hiệu quả hoạt động, tăng sức cạnh tranh như hiện nay là hết sức cần thiết.

Cho đến nay, có nhiều tranh luận trái chiều về sự tác động của việc thuê ngoài đến hiệu quả tổ chức. Phần lớn các nghiên cứu cho rằng, thuê ngoài tác động tích cực đến hiệu quả tài chính của doanh nghiệp (Hirotoshi, 2013; Kroes \& Ghosh, 2010). Tuy vậy, cũng có nghiên cứu cho rằng, thuê ngoài không cải thiện được tài chính doanh nghiệp (chỉ tiêu $\mathrm{ROE}$ ), thậm chí ảnh hưởng tiêu cực đến chỉ tiêu ROA (Anders \& Björn, 2015). Cũng có nghiên cứu cho rằng, thuê ngoài không tác động đến hiệu quả tài chính doanh nghiệp (Gilley et al., 2004). Như vậy, mỗi tác giả có nhận định khác nhau về sự việc tác động việc thuê ngoài dịch vụ đến hiệu quả hoạt động của doanh nghiệp. Do đó, câu hỏi đặt ra là thuê ngoài dịch vụ có tác động đến hiệu quả tài chính của các DNNVV ở Cần Thơ không? Làm thế nào nâng cao được hiệu quả sử dụng nguồn lực bên ngoài cho các doanh nghiệp.

Với những lập luận như trên, nghiên cứu được thực hiện nhằm hiểu rõ hơn về tình hình sử dụng nguồn lực thuê ngoài, các yếu tố ảnh hưởng đến thuê ngoài dịch vụ và nghiên cứu sự tác động của việc sử dụng dịch vụ thuê ngoài đến hiệu quả tài chính của doanh nghiệp nhỏ và vừa tại thành phố Cần Thơ.

\section{Co' sở lý thuyết và mô hình nghiên cứu}

\subsection{Cơ sở lý thuyết}

\subsubsection{Cơ sở lý thuyết của thuê ngoài dịch vu}

Theo lý thuyết chi phí giao dịch (Transaction Cost Economics theory - TCE) của Coase (1937), tiết kiệm chi phí giao dịch có vai trò quan trọng đối với sự cạnh trạnh và tồn tại của doanh nghiệp. Lý thuyết TCE chỉ rõ, để thực hiện được mục tiêu tiết kiệm chi phí thì doanh nghiệp cần tận dụng cơ hội từ sử dụng nguồn lực của các tổ chức bên ngoài. Lý thuyết này trả lời cho câu hỏi “Lý do doanh nghiệp sủ dụng dịch vu thuê ngoài? ”. Điều này phụ thuộc vào sự so sánh chi phí giữa thuê ngoài với chi phí giao dịch nội bộ, có nghĩa khi chi phí thực hiện nội 
bộ lớn hơn chi phí giao dịch bên ngoài thì doanh nghiệp có xu hướng đi thuê dịch vụ bên ngoài thực hiện và ngược lại. Trên cơ sở phát triển lý thuyết TCE của Coase (1937), thì Williamson (1975) cho rằng, doanh nghiệp có thể gặp phải rủi ro về chi chí giao dịch gia tăng do chi phí phát sinh hoặc nguy cơ chủ nghĩa cơ hội của bên cho thuê, điều này có thể làm ảnh hưởng tiêu cực đến hoạt động của doanh nghiệp. Do vậy, quyết định thuê ngoài còn tác động bởi thái độ của chủ doanh nghiệp đối với với hoạt động này như thế nào (Williamson, 1975).

Ngoài ra, theo lý thuyết năng lực cốt lõi (Core Competency Theory - CCT) của Prahalad và Hamel (1990), mỗi tổ chức đều có những thế mạnh về nguồn lực nội bộ cần phát huy để tối đa hóa các nguồn lợi và nắm bắt cơ hội kinh doanh. Theo đó, quyết định sử dụng nguồn lực bên ngoài của doanh nghiệp sẽ phụ thuộc vào bản chất của công việc, thông thường doanh nghiệp chỉ thuê ngoài các hoạt động không cốt lôi. Dựa trên cơ sở phát triển lý thuyết CCT thì Aron và Singh (2005) còn cho rằng việc xem xét sử dụng nguồn lực bên ngoài còn phụ thuộc vào: $(i)$ đánh giá lợi ích từ hoạt động thuê ngoài; (ii) chiến lược của doanh nghiệp; (iii) khả năng đáp ứng yêu cầu của các nhà cung ứng dịch vụ.

Bên cạnh đó, theo lý thuyết mối quan hệ (Relationship Theories - RT) được đề xuất bởi Klepper (1995) cho thấy vai trò quan trọng của sự hợp tác, giao lưu kinh tế của các tổ chức với nhau. Kết quả của mối quan hệ này là hiệu quả về lợi ích của các bên. Theo Klepper (1995) lý thuyết RT tập trung xây dựng một sự thỏa thuận mà ở đó mỗi bên xem xét động lực cho việc xây dựng và duy trì mối quan hệ nhằm có được kết quả cho mình từ mối quan hệ này. Từ đó cho thấy, lý thuyết RT có thể vận dụng trong vấn đề thuê ngoài của doanh nghiệp, bởi lẽ yếu tố mối quan hệ trong thuê ngoài đóng vai trò quan trọng đến quyết định sử dụng dịch vụ.

Như vậy, trên cơ sở lý thuyết cho thấy việc sử dụng nguồn lực bên ngoài phụ thuộc vào 7 yếu tố: (1) lợi ích của thuê ngoài; (2) rủi ro khi thuê ngoài; (3) đặc điểm nguồn lực nội bộ của doanh nghiệp; (4) sự phù hợp của việc thuê ngoài với định hướng chiến lược của doanh nghiệp; (5) khả năng đáp ứng yêu cầu của bên cung cấp; (6) thái độ đối với thuê ngoài và (7) mối quan hệ giữa các bên tham gia.

\subsubsection{Cơ sở lý thuyết về hiệu quả hoạt động}

Để đo lường hiệu quả hoạt động của doanh nghiệp, nhiều nghiên cứu dựa trên cơ sở lý thuyết thẻ điểm cân bằng (Balanced Scorecard - BSC). Theo lý thuyết $\mathrm{BSC}$ của Kaplan và Norton (1992), hiệu quả của một tổ chức được đánh giá từ 4 khía cạnh: (1) hiệu quả tài chính; (2) hiệu quả khách hàng; (3) hiệu quả quy trình nội bộ và (4) hiệu quả đổi mới và phát triển.

Marr (2005) cũng chỉ ra rằng, lý thuyết BSC được các nghiên cứu sử dụng phổ biến nhất. Trong tất cả các chỉ tiêu đánh giá hiệu quả hoạt động, thì hiệu quả về khía cạnh tài chính được hầu hết các doanh nghiệp quan tâm khi đánh giá tình hình hoạt động của mình.

Cho đến nay, có nhiều cách tiếp cận khác nhau về đánh giá hiệu quả tổ chức. Theo đó, Richard, Devinney, Yip, và Johnson (2009) cho rằng đánh giá hiệu quả hoạt động phải dựa vào sự so sánh giữa kết quả đầu ra và giá trị đầu vào của doanh nghiệp. Kroes và Ghosh (2010) thì cho rằng, hiệu quả được đánh giá trên cơ sở mức độ đạt được các chỉ tiêu kinh doanh so với đối thủ cạnh tranh. Trong khi đó, Ondoro (2015) thì cho rằng có nhiều cách tiếp cận khác nhau về việc đánh giá hiệu quả tổ chức chứ không có một cách tiếp cận chung nào, điều này còn tùy 
thuộc mục tiêu của các nhà quản trị cũng như mục tiêu nghiên cứu. Theo đó, hiệu quả tổ chức còn được đánh giá dựa trên cơ sở ước tính các thông số đã đạt được so với mục tiêu doanh nghiệp nhắm đến. Trong nghiên cứu này, tác giả đánh giá sự tác động của thuê ngoài dịch vụ đến hiệu quả hoạt động theo quan điểm của Ondoro (2015).

\subsection{Mô hình nghiên cúu}

Gewald (2010) chỉ ra rằng, thái độ của doanh nghiệp (attitude towards outsourcing) đối với hoạt động thuê ngoài ảnh hưởng bởi việc đánh giá lợi ích cũng như rủi ro của hoạt động này. Đây là 2 yếu tố quan trọng được cân nhắc khi doanh nghiệp thuê ngoài. Và thái độ đối với thuê ngoài sẽ tác động đáng kể đến mức độ thuê ngoài của doanh nghiệp (level of outsourcing). Gewald và Dibbern (2009) cũng đã chứng minh, bên cạnh thái độ đối với hoạt động thuê ngoài ảnh hưởng đến mức độ thuê ngoài thì yếu tố lợi ích và rủi ro cũng ảnh hưởng trực tiếp đến mức độ thuê ngoài của doanh nghiệp. Từ phân tích, nghiên cứu đưa ra các giả thuyết như sau:

H1,2: yếu tố lợi ich tác động tích cực đến thái độ và mức độ thuê ngoài

H3,4: yếu tố rủi ro tác động tiêu cực đến thái độ và mức độ thuê ngoài

\section{H5: thái độ đối với hoạt động thuê ngoài sẽ tác động thuận đến mức độ thuê ngoài}

Bên cạnh đó, Kwok và Jianmei (2006), Kroes và Ghosh (2010) còn lập luận và chỉ ra rằng, quyết định sử dụng các nguồn lực của doanh nghiệp còn phụ thuộc vào chiến lược kinh doanh, bởi chiến lược thuê ngoài phải trên cơ sở phù hợp với mục tiêu và định hướng hoạt động của doanh nghiệp. Do đó, nghiên cứu đề xuất giả thuyết:

H6: có mối quan hệ thuận chiều giữa định hướng chiến lược với mức độ thuê ngoài

Hafeez và Andersen (2014) đã một lần nữa khẳng định mức độ thuê ngoài của doanh nghiệp phụ thuộc vào nhiều yếu tố khác nhau. Theo đó, mức độ thuê ngoài phụ thuộc vào: (i) nhận thức rủi ro thuê ngoài; (ii) tần suất giao dịch trong doanh nghiệp; (iii) yếu tố tài sản của doanh nghiệp; (iv) sự tin tưởng vào bên cung ứng dịch vụ và (v) qui mô hoạt động của tổ chức, nhất là những doanh nghiệp có qui mô nhỏ do yếu/thiếu nguồn lực nội bộ thì xu hướng thuê ngoài càng cao. Như vậy, theo Hafeez và Andersen (2014), mức độ thuê ngoài của doanh nghiệp phụ thuộc chủ yếu vào 3 yếu tố: (1) nhận thức rủi ro của sử dụng nguồn lực bên ngoài; (2) đặc điểm chức năng của doanh nghiệp và (3) nhân tố nhà cung ứng dịch vụ cho doanh nghiệp. Từ đó, nghiên cứu đề xuất 2 giả thuyết:

H7: có mối quan hệ thuận chiều giữa yếu tố đặc điểm chức năng với mức độ thuê ngoài

H8: có mối quan hệ thuận chiều giữa việc đảm bảo các tiêu chuẩn bên cung ứng dịch vu và múc độ thuê ngoài.

Như vậy, so với cơ sở lý thuyết TCE và CCT, thì các nghiên cứu thực nghiệm trên vẫn còn hạn chế trong việc chỉ ra được sự tác động của các yếu tố ảnh hưởng đến mức độ thuê ngoài dịch vụ. Mỗi nghiên cứu chỉ trình bày một khía cạnh hẹp mà chưa chỉ ra được sự tác động một cách đầy đủ và bao quát các yếu tố. Do vậy, trong nghiên cứu này, tác giả trình bày một cách tổng quát sự tác động ấy của các yếu tố đến việc thuê ngoài trong doanh nghiệp. Nhìn chung, mức độ thuê ngoài phụ thuộc vào 6 yếu tố: (1) lợi ích của thuê ngoài, (2) rủi ro của thuê ngoài, (3) thái độ của doanh nghiệp đối với thuê ngoài, (4) định hướng chiến lược, (5) đặc điểm chức 
năng và (6) tiêu chuẩn nhà cung ứng. Thêm vào đó, dựa vào kết quả phỏng vấn sâu (bao gồm 3 doanh nghiệp chuyên cung ứng các loại dịch vu và 5 doanh nghiệp có thuê ngoài các dịch $v u$ ) cho thấy, yếu tố mối quan hệ giữa các bên liên quan cũng tác động đáng kể đến việc đi thuê, đặc biệt là thông qua mối quan hệ quen biết. Điều này hoàn toàn phù hợp với lý thuyết mối quan hệ RT của Klepper (1995). Thật vậy, khi đó doanh nghiệp sẽ tin tưởng và an tâm hơn khi chuyển giao công việc cho bên cung cấp dịch vụ. Mặt khác, doanh nghiệp xem đây là cơ hội để xây dựng và phát triển mối quan hệ lâu dài. Qua phỏng vấn sâu còn cho thấy, doanh nghiệp có xu hướng lựa chọn bên cung cấp dịch vụ địa phương gần nơi doanh nghiệp hoạt động, điều này sẽ giúp tiện lợi trong việc liên lạc, thuận tiện trong việc kiểm soát nhằm giảm thiểu rủi ro. Do đó, nghiên cứu đề xuất thêm giả thuyết như sau:

H9: có mối quan hệ thuận giữa yếu tố mối quan hệ của các bên và mức độ thuê ngoài

Như đã trình bày trên, nhiều nghiên cứu đã chứng minh, việc thuê ngoài đã tác động đến hiệu quả hoạt động, đặc biệt hiệu quả tài chính doanh nghiệp. Đầu tiên, thuê ngoài tác động đến tỷ suất lợi nhuận trên tài sản (ROA - Return on assets). Kroes và Ghosh (2010) và Anders và Björn (2015) cho rằng, nhờ vào giảm được chi phí do không phải đầu tư nhiều vào tài sản cố định. Do đó sẽ cải thiện chỉ tiêu ROA. Bên cạnh đó, nhiều nghiên cứu cũng đã khẳng định, nhờ thuê ngoài mà doanh nghiệp tập trung mọi nguồn lực vào mục tiêu phục vụ khách hàng, điều này phần nào cải thiện doanh thu cũng như chỉ tiêu tỷ suất lợi nhuận trên doanh thu (ROS - Return on sales) (Hirotoshi, 2013; Kroes \& Ghosh, 2010). Thêm vào đó, thuê ngoài dịch vụ còn tác động đến chỉ tiêu tỷ số lợi nhuận trên vốn chủ sở hữu của doanh nghiệp (ROE - Return On common Equity) (Bustinza, Arias-Aranda, \& Gutierrez-Gutierrez, 2010). Mặc dù chưa chứng minh được sự tác động này, nhưng Anders và Björn (2015) cho rằng chỉ tiêu $\mathrm{ROE}$ là một trong những chỉ tiêu quan trọng nhất để đánh giá hiệu quả hoạt động của tổ chức. Dựa trên kết quả phỏng vấn sâu, nghiên cứu đề xuất đánh giá hiệu quả tài chính doanh nghiệp ở cả 3 chỉ tiêu: (i) ROA, (ii) ROS và (iii) ROE. Đây được xem là các chỉ tiêu cần thiết và quan trọng trong việc đánh giá hiệu quả hoạt động của tổ chức. Từ phân tích, nghiên cứu kỳ vọng:

H10: có mối quan hệ tích cực giña việc thuê ngoài với hiệu quả tài chính doanh nghiệp

Từ cơ sở lý thuyết, lược khảo các nghiên cứu liên quan và qua kết quả phỏng vấn chuyên sâu, nghiên cứu đề xuất mô hình sự tác động của thuê ngoài dịch vụ đến hiệu quả tài chính của các DNNVV tại thành phố Cần Thơ như sau: 


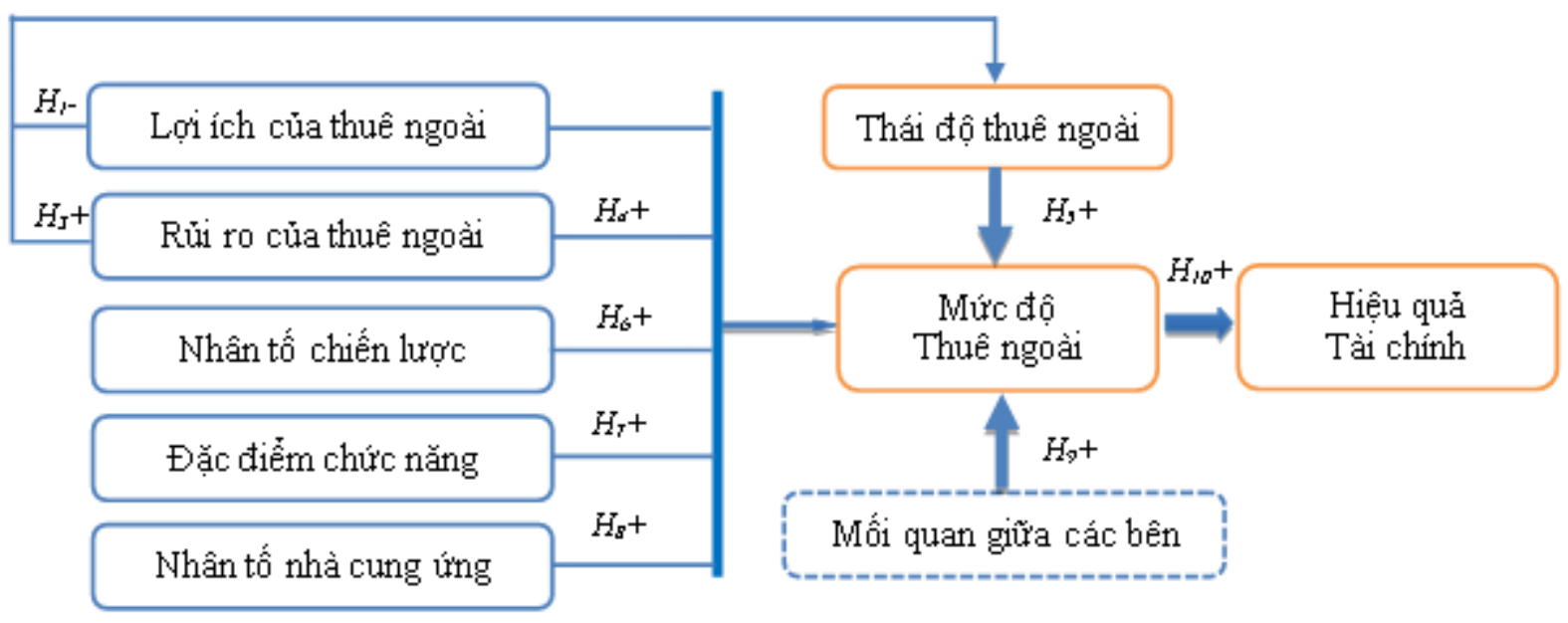

Hình 1. Mô hình nghiên cứu dự kiến

\section{Bảng 1}

Diễn giải các biến trong mô hình nghiên cứu

\begin{tabular}{|c|c|c|}
\hline $\begin{array}{l}\text { Mã } \\
\text { hóa }\end{array}$ & Nội dung & Nguồn trích dẫn \\
\hline \multicolumn{3}{|c|}{$\begin{array}{l}\text { 1. Lợi ích của thuê ngoài: } 1=\text { hoàn toàn không đồng ý } \rightarrow 5=\text { hoàn hoàn đồng ý với các } \\
\text { phát biểu }\end{array}$} \\
\hline LI1 & Tiết kiệm chi phí hơn cho doanh nghiệp & \multirow{6}{*}{$\begin{array}{l}\text { Gewald và Dibbern (2009); } \\
\text { Gewald (2010) }\end{array}$} \\
\hline LI2 & Chuyển đổi chi phí cố định sang chi phí biến đổi & \\
\hline LI3 & Tập trung thực hiện các chức năng cốt lõi & \\
\hline LI4 & Tiếp cận đội ngủ nhân viên chuyên môn cao & \\
\hline LI5 & Chia sẽ rủi ro với nhà cung ứng & \\
\hline LI6 & Giải quyết vấn đề thiếu nguồn lực & \\
\hline LI7 & $\begin{array}{l}\text { Giúp giải phóng một phần công việc không quan } \\
\text { trọng }\end{array}$ & Phỏng vấn chuyên sâu \\
\hline \multicolumn{3}{|c|}{$\begin{array}{l}\text { 2. Rủi ro của thuê ngoài: } 1=\text { hoàn toàn không đồng ý } \rightarrow 5=\text { hoàn hoàn đồng ý với các } \\
\text { phát biểu }\end{array}$} \\
\hline RR1 & Phụ thuộc nhà cung ứng & \multirow{6}{*}{$\begin{array}{l}\text { Gewald và Dibbern (2009); } \\
\text { Gewald (2010); Hafeez và } \\
\text { Andersen (2014) }\end{array}$} \\
\hline RR2 & Mất khả năng kiểm soát & \\
\hline RR3 & Gián đoạn quá trình thực hiện công việc & \\
\hline RR4 & Chi phí giảm không như mong đợi & \\
\hline RR5 & Chi phí cao hơn mức mong đợi & \\
\hline RR6 & Nguy cơ bị lộ bí mật, thông tin doanh nghiệp & \\
\hline \multicolumn{3}{|c|}{ 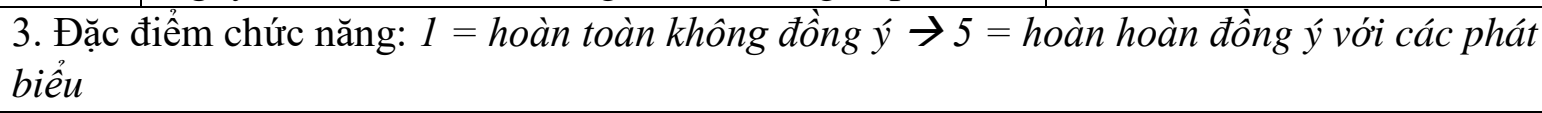 } \\
\hline CN1 & $\begin{array}{l}\text { Doanh nghiệp thuê ngoài những công việc kém } \\
\text { quan trọng }\end{array}$ & \multirow{2}{*}{ Hafeez và Andersen (2014) } \\
\hline $\mathrm{CN} 2$ & $\begin{array}{l}\text { Thuê ngoài các phần việc không đòi hỏi thông tin } \\
\text { bảo mật }\end{array}$ & \\
\hline
\end{tabular}




\begin{tabular}{|l|l|}
\hline CN3 & $\begin{array}{l}\text { Tài sản, trang thiết bị, công cụ hỗ trợ thực hiện } \\
\text { công việc }\end{array}$ \\
\hline CN4 & Chất lượng nhân sự thực hiện công việc \\
\hline CN5 & Qui mô hoạt động của doanh nghiệp \\
\hline CN6 & Khối lượng công việc cần xử lý \\
\hline
\end{tabular}

4. Định hướng chiến lược: $1=$ hoàn toàn chua có chiến lực $\rightarrow 5=$ luôn luôn sủ dụng chiến lược sau

\begin{tabular}{|c|c|c|}
\hline CL1 & Xu hướng thuê ngoài của doanh nghiệp & \multirow{5}{*}{$\begin{array}{l}\text { Kwok và Jianmei (2006); } \\
\text { Kroes và Ghosh (2010) }\end{array}$} \\
\hline CL2 & Chiến lược cạnh tranh so với đối thủ & \\
\hline CL3 & Chiến lược cải tiến sản phẩm/dịch vụ & \\
\hline CL4 & Chiến lược mở rộng qui mô kinh doanh & \\
\hline CL5 & Chiến lược đa dạng hóa kinh doanh & \\
\hline \multicolumn{3}{|c|}{ 5. Nhà cung ứng: $1=$ hoàn toàn không đồng ý $\rightarrow 5=$ hoàn hoàn đồng ý với các phát biểu } \\
\hline $\mathrm{CC} 1$ & Giá cả dịch vụ & \multirow{6}{*}{$\begin{array}{l}\text { Azurin, Shahin, và } \\
\text { Sulaiman (2013); Hafeez và } \\
\text { Andersen (2014) }\end{array}$} \\
\hline $\mathrm{CC} 2$ & Danh tiếng nhà cung ứng & \\
\hline CC3 & Chuyên môn của bên cung ứng dịch vụ & \\
\hline $\mathrm{CC} 4$ & Đảm bảo kế hoạch & \\
\hline CC5 & Dịch vụ khách hàng & \\
\hline CC6 & Khả năng điều chỉnh công việc theo yêu cầu & \\
\hline CC7 & Có nét văn hoá tương đồng với doanh nghiệp & Phỏng vấn chuyên sâu \\
\hline
\end{tabular}

6. Mối quan hệ giữa các bên: $1=$ hoàn toàn không đồng ý $\rightarrow 5=$ hoàn hoàn đồng ý với các phát biểu

\begin{tabular}{|l|l|l|}
\hline QH1 & Mối quan hệ quen biết với nhà cung ứng & Phỏng vấn chuyên sâu \\
\hline QH2 & Xây dựng mối quan hệ trong dài hạn & Phỏng vấn chuyên sâu \\
\hline QH3 & Vị trí địa lý nhà cung ứng & Phỏng vấn chuyên sâu \\
\hline
\end{tabular}

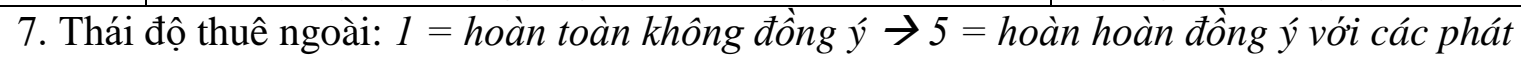
biểu

\begin{tabular}{|c|c|c|}
\hline TD1 & $\begin{array}{l}\text { Doanh nghiệp có thái độ tích cực đối với hoạt động } \\
\text { thuê ngoài }\end{array}$ & \multirow{6}{*}{$\begin{array}{l}\text { Gewald và Dibbern (2009); } \\
\text { Gewald (2010) }\end{array}$} \\
\hline TD2 & $\begin{array}{l}\text { Thuê ngoài phù hợp với mục tiêu hoạt động của } \\
\text { doanh nghiệp }\end{array}$ & \\
\hline TD3 & $\begin{array}{l}\text { Thuê ngoài phù hợp với định hướng chiến lược } \\
\text { doanh nghiệp }\end{array}$ & \\
\hline TD4 & Thuê ngoài thực hiện các công việc sẽ tốt hơn & \\
\hline TD5 & $\begin{array}{l}\text { Lợi ích khi thuê ngoài nhiều hơn rủi ro chúng tôi } \\
\text { gặp phải }\end{array}$ & \\
\hline TD6 & Sự tin tưởng, ủng hộ hoạt động thuê ngoài & \\
\hline \multicolumn{3}{|c|}{$\begin{array}{l}\text { 8. Mức độ thuê ngoài: } 1=\text { hoàn toàn không đồng ý } \rightarrow 5=\text { hoàn hoàn đồng ý với các phát } \\
\text { biểu }\end{array}$} \\
\hline MD1 & Thuê ngoài là rất quan trọng tại doanh nghiệp & \multirow{3}{*}{$\begin{array}{l}\text { Gewald và Dibbern (2009); } \\
\text { Gewald (2010); Hafeez và } \\
\text { Andersen (2014) }\end{array}$} \\
\hline MD2 & Thuê ngoài là mục tiêu lâu dài của doanh nghiệp & \\
\hline MD3 & Doanh nghiệp sẽ tăng cường mức độ thuê ngoài & \\
\hline
\end{tabular}




\begin{tabular}{|c|c|c|}
\hline MD4 & $\begin{array}{l}\text { Doanh nghiệp sẽ tăng cường hơn nữa hoạt động } \\
\text { thuê ngoài }\end{array}$ & \\
\hline MD5 & Đánh giá chung mức độ (tỷ lệ) thuê ngoài & \\
\hline \multicolumn{3}{|c|}{ 9. Hiệu quả tài chính: $1=$ hoàn toàn không đạt $\rightarrow 5=$ đạt được rất cao } \\
\hline ROS & $\begin{array}{l}\text { Mức độ đạt được tỷ suất giữa lợi nhuận và doanh } \\
\text { thu thuần }\end{array}$ & \multirow{3}{*}{$\begin{array}{l}\text { Kroes và Ghosh (2010); } \\
\text { Bustinza và cộng sự, 2010; } \\
\text { Hirotoshi (2013); Anders và } \\
\text { Björn (2015) }\end{array}$} \\
\hline ROE & $\begin{array}{l}\text { Mức độ đạt được tỷ suất giữa lợi nhuận và vốn chủ } \\
\text { sở hữu }\end{array}$ & \\
\hline ROA & Mức độ đạt được tỷ suất giữa lợi nhuận và tài sản & \\
\hline
\end{tabular}

Nguồn: Lược khảo các nghiên cứu liên quan và phỏng vấn chuyên sâu

\section{Phương pháp nghiên cứu}

\subsection{Phương pháp thu thập số liệu}

- Số liệu thư cấp: các thông tin, số liệu liên quan về hoạt động thuê ngoài nói chung và tình hình hoạt động của DNNVV ở TP. Cần Thơ nói riêng được thu thập từ các bài báo, các tạp chí chuyên ngành.

- Số liệu sơ cấp: nghiên cứu tiến hành chọn mẫu bằng phương pháp phi xác suất theo kiểu thuận tiện kết hợp lấy mẫu theo phương pháp phát triển trên cơ sở mối quan hệ. Doanh nghiệp phỏng vấn là DNNVV tập trung chủ yếu ở các quận Ninh Kiều, Cái Răng, Bình Thủy, Ô Môn, Thốt Nốt. Đối tượng phỏng vấn là chủ các doanh nghiệp, hoặc giám đốc/phó giám đốc, hoặc trưởng/phó các phòng ban trong doanh nghiệp. Việc điều tra được tiến hành từ tháng 01 đến tháng 12/2017, nghiên cứu thu được 153 quan sát có đầy đủ thông tin cần thiết.

\subsection{Phương pháp phân tích}

Để giải quyết mục tiêu nghiên cứu, tác giả sử dụng các phương pháp: (1) phân tích định tính qua việc phỏng vấn chuyên sâu các doanh nghiệp chuyên cung cấp dịch vụ thuê ngoài và các doanh nghiệp có sử dụng dịch vụ thuê ngoài; (2) phân tích định lượng thông qua: (i) kiểm định Cronbach's Alpha để đánh giá độ tin cậy và chất lượng của thang đo; (ii) phân tích nhân tố khẳng định (Confirmatory Factor Analysis - CFA) để xác định sự phù hợp của dữ liệu nghiên cứu với mô hình lý thuyết và (iii) mô hình cấu trúc tuyến tính (Structural equation modeling $S E M)$ để đánh giá sự tác động của việc thuê ngoài đến hiệu quả tài chính của các DNNVV ở Thành phố Cần Thơ.

\section{Kết quả nghiên cứu}

\subsection{Thông tin chung}

Kết quả điều tra 153 doanh nghiệp có sử dụng dịch vụ thuê ngoài tại Cần Thơ cho thấy được thông tin của doanh nghiệp như bảng sau:

\section{Bảng 2}


Thông tin về doanh nghiệp được điều tra

\begin{tabular}{ccc}
\hline Chỉ tiêu & Số doanh nghiệp & Tỷ trọng (\%) \\
\hline Loại hình doanh nghiệp: & 51 & \\
- Công ty cổ phần & 87 & 33,33 \\
- Công ty TNHH & 14 & 56,86 \\
- Doanh nghiệp tư nhân & 1 & 9,15 \\
- Hợp tác xã & & 0,65 \\
\hline Lĩnh vực hoạt động: & 29 & 18,95 \\
- Nông - Lâm - Thủy sản & 50 & 32,68 \\
- Công nghiệp - Xây dựng & 74 & 48,37 \\
- Thuoong mại - Dịch vụ & & \\
Quy mô doanh nghiệp ${ }^{1}$ - Siêu nhỏ & 95 & 62,09 \\
- Doanh nghiệp nhỏ & 56 & 36,60 \\
- Doanh nghiệp vìa & 2 & 1,31 \\
\hline
\end{tabular}

Nguồn: Kết quả xử lý từ số liệu điều tra 153 doanh nghiệp

Kết quả nghiên cứu cho thấy, phần lớn doanh nghiệp thuê ngoài dịch vụ tại Cần Thơ là công ty TNHH và công ty Cổ phần (chiếm đến $90,19 \%$ tổng số doanh nghiệp điều tra). Đa phần doanh nghiệp hoạt động trong lĩnh vực thương mại - dịch vụ (chiếm 48,37\%) và lĩnh vực công nghiệp - xây dựng (chiếm 32,68\%). Điều này cũng phần nào cho thấy được, các doanh nghiệp trong 2 lĩnh vực này có nhu cầu sử dụng dịch vụ rất cao trong hoạt động kinh doanh của mình. Kết quả điều tra còn cho thấy, doanh nghiệp có nhu cầu sử dụng dịch vụ thuê ngoài chủ yếu là doanh nghiệp có qui mô siêu nhỏ (chiếm đến $62,09 \%$ trong tổng số doanh nghiệp điều tra) và doanh nghiệp qui mô nhỏ (chiếm 36,60\%). Qua đó cho thấy, doanh nghiệp có qui mô nhỏ và siêu nhỏ có nhu cầu sử dụng dịch vụ thuê ngoài cao hơn các doanh nghiệp có qui mô vừa.

\footnotetext{
${ }^{1}$ Căn cứ vào số lao động theo Nghị định số 56/2009/NĐCP ngày 30 tháng 6 năm 2009
} 
Các dịch vụ thuê ngoài được doanh nghiệp tỉnh ở Cần Thơ sử dụng khá đa dạng. Tuy nhiên, đa phần doanh nghiệp sử dụng dịch vụ thuê bảo vệ chuyên nghiệp (chiếm đến 52,29\% số doanh nghiệp điều tra). Bên cạnh đó, doanh nghiệp ở địa phương còn quan tâm sử dụng dịch vụ như vệ sinh công nghiệp, thuê ngoài kế toán doanh nghiệp và thuê nhân sự bán thời gian trong hoạt động của mình. Chi tiết các dịch vụ được trình bày ở hình sau:

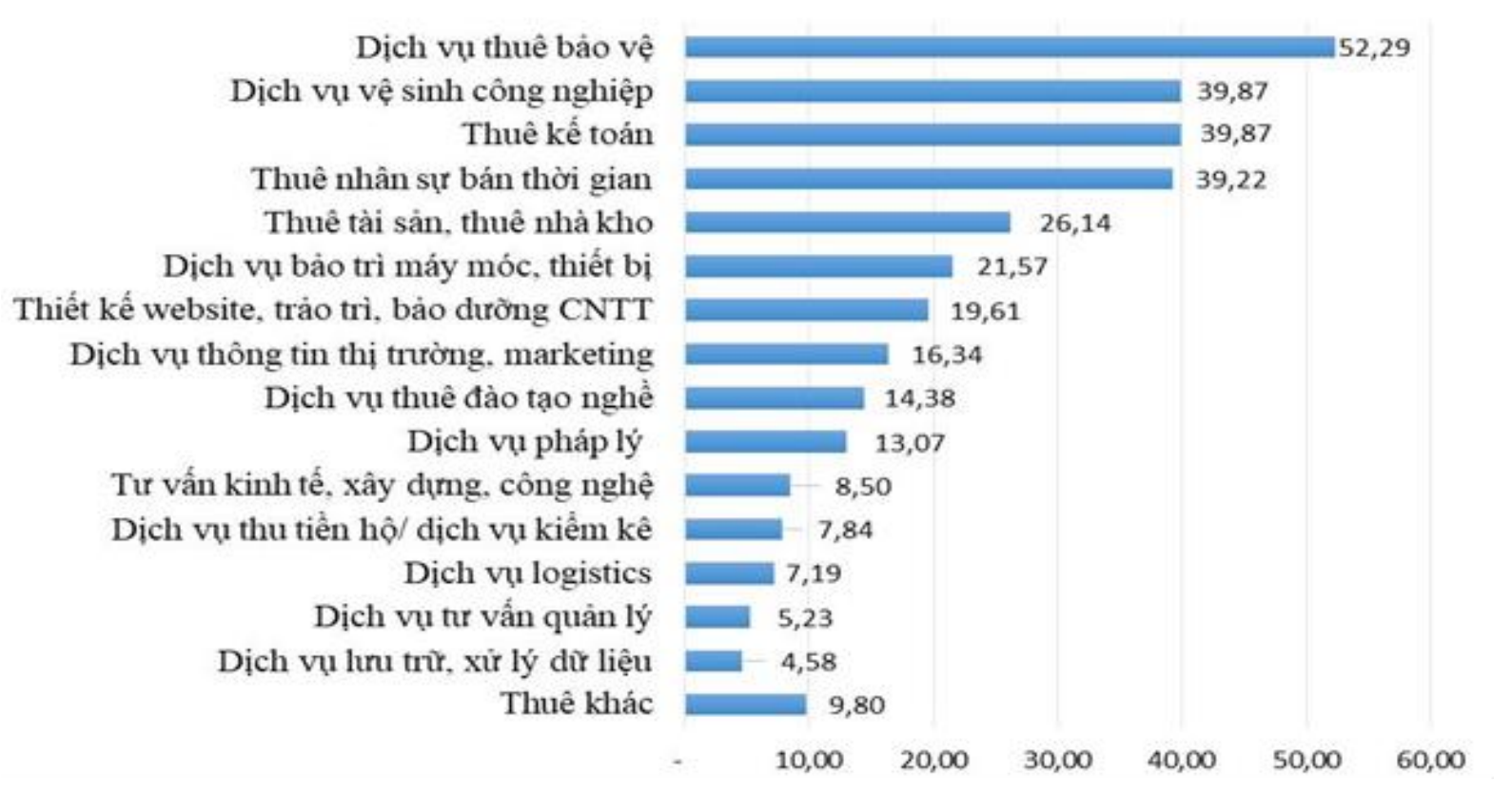

Hình 2. Các dịch vụ được doanh nghiệp thuê ngoài

Nguồn: Kết quả xử lý từ số liệu điều tra 153 doanh nghiệp

Tuy vậy, bên cạnh các dịch vụ được quan tâm thì cũng có khá nhiều dịch vụ chưa được doanh nghiệp quan tâm sử dụng như: dịch vụ lưu trữ, xử lý dữ liệu (chỉ có 4,58\% doanh nghiệp thuê), các dịch vụ tư vấn quản lý, dịch vụ logistics, dịch vụ thu tiền hộ, kiểm kê hay dịch vụ thuê tư vấn kinh tế, xây dựng và công nghệ cũng chiếm tỷ lệ rất ít doanh nghiệp thuê (chưa đến $10 \%$ doanh nghiệp lựa chọn). Điều này có thể cho thấy, thuê ngoài vẫn chứa đựng những rủi ro nhất định, nhất là vấn đề thông tin doanh nghiệp có thể bị lộ ra bên ngoài.

\subsection{Hiệu quả sủ̉ dụng dịch vụ thuê ngoài}

\subsubsection{Kiểm định độ tin cậy của thang đo trong mô hình}

Kết quả kiểm định Cronbach's Alpha cho thấy hầu hết thang đo của các khái niệm đạt được độ tin cậy tốt do hệ số Cronbach's Alpha lớn hơn 0,60 và hệ số tương quan biến tổng (item-total correlation) của các biến đều lớn hơn 0,3 (Hoyle, 1995). Tuy nhiên, biến CN1 (Doanh nghiệp thuê ngoài nhũng công việc kém quan trọng) đo lường khái niệm đặc điểm chức năng, biến CL5 (Chiến luợc đa dạng hóa kinh doanh) đo lường khái niệm định hướng chiến lược của doanh nghiệp, biến CC7 (Sư tuơng đồng về văn hóa với doanh nghiệp) đo lường cho khái niệm tiêu chuẩn nhà cung cấp dịch vụ có hệ số tương quan biến tổng nhỏ hơn 0,3 nên biến này bị loại. Kết quả kiểm định Cronbach’s Alpha lần 2 cho bảng số liệu sau: 


\section{Bảng 3}

Kết quả kiểm định độ tin cậy của thang đo

\begin{tabular}{clclc}
\hline STT & \multicolumn{1}{c}{ Thang đo } & $\begin{array}{c}\text { Số } \\
\text { biến }\end{array}$ & \multicolumn{1}{c}{ Ký hiệu } & $\begin{array}{c}\text { Cronbach's } \\
\text { alpha }\end{array}$ \\
\hline 1 & Lợi ích thuê ngoài & 7 & $\begin{array}{l}\text { LI1, LI2, LI3, LI4, LI5, LI6, } \\
\text { LI7 }\end{array}$ & 0,767 \\
\hline 2 & Rủi ro của thuê ngoài & 6 & $\begin{array}{l}\text { RR1, RR2, RR3, RR4, RR5, } \\
\text { RR6 }\end{array}$ & 0,838 \\
\hline 3 & Đặc điểm chức năng & 5 & CN2, CN3, CN4, CN5, CN6 & 0,750 \\
\hline 4 & Định hướng chiến lược & 4 & CL1, CL2, CL3, CL4 & 0,745 \\
\hline 5 & Nhà cung ứng & 6 & $\begin{array}{l}\text { CC1, CC2, CC3, CC4, CC5, } \\
\text { CC6 }\end{array}$ & 0,816 \\
\hline 6 & $\begin{array}{l}\text { Mối quan hệ giữa các } \\
\text { bên }\end{array}$ & 3 & QH1, QH2, QH3 & 0,786 \\
\hline 7 & Thái độ thuê ngoài & 6 & $\begin{array}{l}\text { TD1, TD2, TD3, TD4, TD5, } \\
\text { TD6 }\end{array}$ & 0,838 \\
\hline 8 & Mức độ thuê ngoài & 5 & MD1, MD2, MD3, MD4, MD5 & 0,804 \\
\hline
\end{tabular}

Nguồn: Kết quả xử lý từ số liệu điều tra 153 doanh nghiệp

\subsubsection{Phân tích CFA cho các khái niệm trong mô hình nghiên cúu}

Nguyen và Nguyen (2008) cho rằng mô hình nghiên cứu phù hợp khi các chỉ số TLI, $\mathrm{CFI} \geq 0,9 ; \mathrm{CMIN} / \mathrm{df} \leq 2 ; \mathrm{RMSEA} \leq 0,08$. Kết quả phân tích CFA của mô hình tới hạn cho thấy, kiểm định Chi-bình phương có $P_{-}$value là 0,00 (nhỏ hơn 0,05 ). Các chỉ tiêu $\mathrm{CMIN} / \mathrm{df}=1,321 \leq$ 2; TLI $=0,900 \geq 0,9 ; \mathrm{CFI}=0,913 \geq 0,9$ và $\mathrm{RMSEA}=0,046 \leq 0,08$ cho thấy được sự phù hợp của mô hình này với dữ liệu thu thập. Tuy nhiên, trọng số đã chuẩn hóa của một số biến nhỏ hơn 0,5 nên các biến này sẽ bị loại ra khỏi mô hình nghiên cứu, bao gồm: (1) biến LI3, LI4, LI6, LI7 của thang đo lợi ích thuê ngoài; (2) biến RR4 của thang đo rủi ro thuê ngoài; (3) biến CC1, CC2, CC5 của thang đo tiêu chuẩn nhà cung ứng; (4) biến $\mathrm{CN} 4, \mathrm{CN} 6$ của thang đo đặc điểm chức năng; (5) biến CL1 của thang đo định hướng chiến lược; (6) biến TD4, TD5 của thang đo thái độ thuê ngoài; (7) biến MD1, MD5 của thang đo mức độ thuê ngoài. 


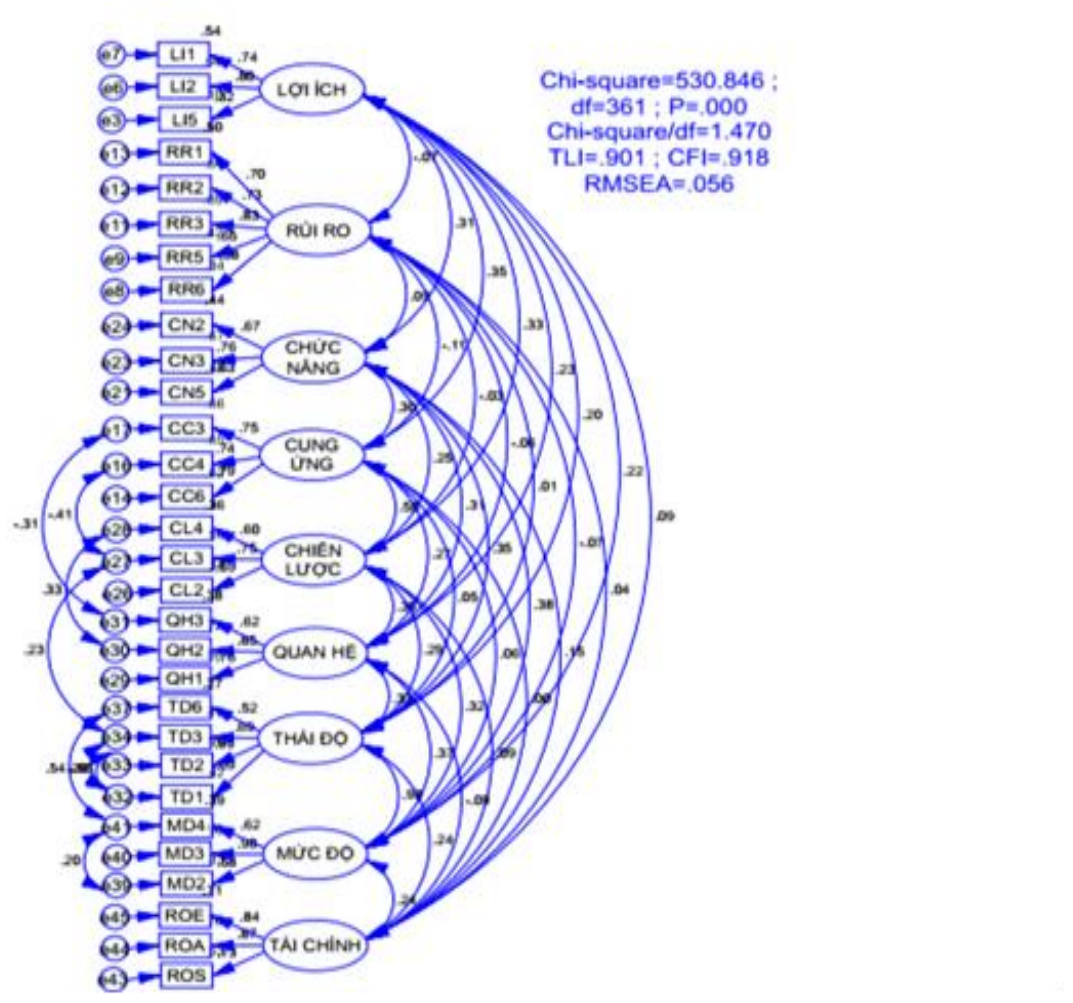

Hình 3. Mô hình tới hạn đo lường các khái niệm trong mô hình (chuẩn hóa)

Nguồn: Kết quả xử lý từ số liệu điều tra 153 doanh nghiệp.

Kết quả cũng cho thấy bên cạnh các thang đo đạt được tính đơn hướng, thì các thang đo (1) mức độ thuê ngoài, (2) thái độ thuê ngoài, (3) quan hệ giữa các bên liên quan, (4) định hướng chiến lược và (5) tiêu chuẩn bên cung ứng dịch vụ không đạt được tính này do sai số của các biến quan sát có tương quan với nhau. Bên cạnh đó, kết quả kiểm định ở Bảng 4 còn cho thấy, các khái niệm đạt giá trị phân biệt do các giá trị $\mathrm{P}_{-}$value đều < 0,05 nên hệ số tương quan của từng cặp khái niệm < 1 ở độ tin cậy $95 \%$, do đó các khái niệm đạt giá trị phân biệt.

\section{Bảng 4}

Kết quả kiểm định giá trị phân biệt giữa các khái niệm

\begin{tabular}{|l|c|l|c|c|c|c|}
\hline \multicolumn{2}{|c|}{ Mối quan hệ } & $\begin{array}{c}\text { Ước } \\
\text { lượng }\end{array}$ & SE & CR & P_value \\
\hline Lợi ích thuê ngoài & $<-->$ & Rủi ro thuê ngoài & $-0,068$ & 0,081 & 13,154 & 0,000 \\
\hline Lợi ích thuê ngoài & $<-->$ & Đặc điểm chức năng & 0,307 & 0,077 & 8,948 & 0,000 \\
\hline Lợi ích thuê ngoài & $<-->$ & Nhà cung ứng & 0,350 & 0,076 & 8,527 & 0,000 \\
\hline Lợi ích thuê ngoài & $<-->$ & $\begin{array}{l}\text { Định hướng chiến } \\
\text { lược }\end{array}$ & 0,328 & 0,077 & 8,741 & 0,000 \\
\hline Lợi ích thuê ngoài & $<-->$ & Mối quan hệ & 0,228 & 0,079 & 9,743 & 0,000 \\
\hline
\end{tabular}




\begin{tabular}{|c|c|c|c|c|c|c|}
\hline \multicolumn{3}{|c|}{ Mối quan hệ } & \multirow{2}{*}{$\begin{array}{c}\begin{array}{c}\text { Ước } \\
\text { lượng }\end{array} \\
0,201 \\
\end{array}$} & \multirow{2}{*}{$\begin{array}{c}\mathbf{S E} \\
0,080 \\
\end{array}$} & \multirow{2}{*}{$\begin{array}{c}\text { CR } \\
10,023 \\
\end{array}$} & \multirow{2}{*}{$\begin{array}{c}\mathbf{P}_{\text {_value }} \\
0,000 \\
\end{array}$} \\
\hline Lợi ích thuê ngoài & $<-->$ & Thái độ thuê ngoài & & & & \\
\hline Lợi ích thuê ngoài & $<->$ & Mức độ thuê ngoài & 0,222 & 0,079 & 9,805 & 0,000 \\
\hline Lợi ích thuê ngoài & $<-->$ & Hiệu quả tổ chức & 0,093 & 0,081 & 11,194 & 0,000 \\
\hline Rủi ro thuê ngoài & $\langle->$ & Đặc điểm chức năng & 0,088 & 0,081 & 11,250 & 0,000 \\
\hline Rủi ro thuê ngoài & $<-->$ & Nhà cung ứng & $-0,105$ & 0,081 & 13,654 & 0,000 \\
\hline Rủi ro thuê ngoài & $<-->$ & $\begin{array}{l}\text { Định hướng chiến } \\
\text { lược }\end{array}$ & $-0,025$ & 0,081 & 12,599 & 0,000 \\
\hline Rủi ro thuê ngoài & $<-->$ & Mối quan hệ & $-0,056$ & 0,081 & 12,997 & 0,000 \\
\hline Rủi ro thuê ngoài & $\langle->$ & Thái độ thuê ngoài & 0,008 & 0,081 & 12,190 & 0,000 \\
\hline Rủi ro thuê ngoài & $<-->$ & Mức độ thuê ngoài & $-0,067$ & 0,081 & 13,141 & 0,000 \\
\hline Rủi ro thuê ngoài & $<-->$ & Hiệu quả tổ chức & 0,039 & 0,081 & 11,818 & 0,000 \\
\hline Nhà cung ứng & $<-->$ & Đặc điểm chức năng & 0,301 & 0,078 & 9,007 & 0,000 \\
\hline Đặc điểm chức năng & $<->$ & $\begin{array}{l}\text { Định hướng chiến } \\
\text { lược }\end{array}$ & 0,249 & 0,079 & 9,529 & 0,000 \\
\hline Đặc điểm chức năng & $\langle->$ & Mối quan hệ & 0,307 & 0,077 & 8,948 & 0,000 \\
\hline Đặc điểm chức năng & $\langle-->$ & Thái độ thuê ngoài & 0,349 & 0,076 & 8,536 & 0,000 \\
\hline Đặc điểm chức năng & $<-->$ & Mức độ thuê ngoài & 0,383 & 0,075 & 8,208 & 0,000 \\
\hline Đặc điểm chức năng & $<->$ & Hiệu quả tổ chức & 0,149 & 0,080 & 10,575 & 0,000 \\
\hline Nhà cung ứng & $<-->$ & $\begin{array}{l}\text { Định hướng chiến } \\
\text { lược }\end{array}$ & 0,583 & 0,066 & 6,307 & 0,000 \\
\hline $\begin{array}{l}\text { Định hướng chiến } \\
\text { lược }\end{array}$ & $<-->$ & Mối quan hệ & 0,347 & 0,076 & 8,556 & 0,000 \\
\hline $\begin{array}{l}\text { Định hướng chiến } \\
\text { lược }\end{array}$ & $<-->$ & Thái độ thuê ngoài & 0,293 & 0,078 & 9,087 & 0,000 \\
\hline $\begin{array}{l}\text { Định hướng chiến } \\
\text { lược }\end{array}$ & $<-->$ & Mức độ thuê ngoài & 0,317 & 0,077 & 8,849 & 0,000 \\
\hline $\begin{array}{l}\text { Định hướng chiến } \\
\text { lược }\end{array}$ & $<-->$ & Hiệu quả tổ chức & 0,093 & 0,081 & 11,194 & 0,000 \\
\hline Mối quan hệ & $<-->$ & Thái độ thuê ngoài & 0,326 & 0,077 & 8,761 & 0,000 \\
\hline Mối quan hệ & $<-->$ & Mức độ thuê ngoài & 0,373 & 0,076 & 8,304 & 0,000 \\
\hline
\end{tabular}




\begin{tabular}{|l|c|l|c|c|c|c|}
\hline \multicolumn{2}{|c|}{ Mối quan hệ } & $\begin{array}{c}\text { Ước } \\
\text { lượng }\end{array}$ & SE & CR & P_value \\
\hline Mối quan hệ & $<-->$ & Hiệu quả tổ chức & $-0,091$ & 0,081 & 13,462 & 0,000 \\
\hline Thái độ thuê ngoài & $<-->$ & Hiệu quả tổ chức & 0,244 & 0,079 & 9,579 & 0,000 \\
\hline Mức độ thuê ngoài & $<-->$ & Hiệu quả tổ chức & 0,243 & 0,079 & 9,590 & 0,000 \\
\hline Nhà cung ứng & $<-->$ & Mối quan hệ & 0,269 & 0,078 & 9,326 & 0,000 \\
\hline Nhà cung ứng & $<-->$ & Thái độ thuê ngoài & 0,054 & 0,081 & 11,642 & 0,000 \\
\hline Nhà cung ứng & $<-->$ & Mức độ thuê ngoài & 0,060 & 0,081 & 11,572 & 0,000 \\
\hline Nhà cung ứng & $<-->$ & Hiệu quả tổ chức & 0,000 & 0,081 & 12,288 & 0,000 \\
\hline
\end{tabular}

Nguồn: Kết quả xử lý từ số liệu điều tra 153 doanh nghiệp

Đánh giá độ tin cậy của thang đo: Theo lý thuyết, để đảm bảo độ tin cậy thì $\rho_{c}$ và $\rho_{v c}$ phải đạt giá trị từ 0,5 trở lên (Fornell \& Larcker, 1981; Hair, Anderson, Tatham, \& Black, 1998). Tuy nhiên, phương sai trích vẫn có thể chấp nhận giá trị từ 0,4 trở lên nhưng phải đảm bảo độ tin cậy tổng hợp phải lớn hơn 0,6 (Fornell \& Larcker, 1981; Fraering và Minor, 2006). Từ kết quả xử lý số liệu ta có Bảng 5 , tóm tắt kết quả kiểm định thang đo cho các khái niệm trong mô hình nghiên cứu như sau:

\section{Bảng 5}

Tóm tắt kết quả kiểm định thang đo các khái niệm trong mô hình

\begin{tabular}{lcccc}
\hline \multicolumn{1}{c}{ Khái niệm } & $\begin{array}{c}\text { Số } \\
\text { biến }\end{array}$ & $\begin{array}{c}\text { Độ tin cậy tổng hộp } \\
-\rho_{c}\end{array}$ & $\begin{array}{c}\text { Tổng phương sai trích } \\
-\rho_{v c}\end{array}$ & Giá trị \\
\hline Lợi ích thuê ngoài & 3 & 0,660 & 0,415 \\
Rủi ro của thuê ngoài & 5 & 0,828 & 0,494 \\
Đặc điểm chức năng & 3 & 0,751 & 0,502 & \\
Định hướng chiến & 3 & & & \\
lược & & 0,702 & 0,443 & Đạt yêu \\
Nhà cung ứng & 3 & 0,803 & 0,574 & cầu \\
Mối quan hệ & 3 & 0,781 & 0,549 & \\
Thái độ thuế ngoài & 4 & 0,800 & 0,505 & \\
Mức độ thuê ngoài & 3 & 0,780 & 0,558 & 0,668 \\
Hiệu quả tổ chức & 3 & 0,858 &
\end{tabular}

Nguồn: Kết quả xử lý từ số liệu điều tra 153 doanh nghiệp

Như vậy, kết quả nghiên cứu cho thấy, tất cả các khái niệm trong mô hình đều đạt yêu cầu về giá trị cũng như độ tin cậy. Do đó, thang đo phù hợp sử dụng cho phân tích SEM.

\subsubsection{Kiểm định mô hình lý thuyết bằng SEM}

Kết quả phân tích SEM lần 1 cho thấy mô hình có Chi-bình phương là 528,408 với $\mathrm{p}=0,000$. Các chỉ tiêu CMIN/df và chỉ tiêu RMSEA của mô hình đáp ứng được yêu cầu của nghiên cứu này do $\mathrm{CMIN} / \mathrm{df}=1,432<2$ và $\mathrm{RMSEA}=0,053<0,8$. Ngoài ra, Các chỉ tiêu khác 
cũng đạt yêu cầu về lý thuyết ( $\mathrm{TLI}=0,909$ và $\mathrm{CFI}=0,923>0,9)$. Điều này cho thấy mô hình này rất thích hợp với dữ liệu thị trường. Ở độ tin cậy $95 \%$ nghiên cứu đã tìm ra mối quan hệ giữa các khái niệm trong mô hình, ta có bảng sau:

\section{Bảng 6}

Các trọng số chưa chuẩn hóa trong mô hình SEM 1

\begin{tabular}{|l|l|l|c|c|c|c|}
\hline \multicolumn{2}{|c|}{ Mối quan hệ } & $\begin{array}{c}\text { Hệ số } \\
\text { tương quan }\end{array}$ & $\begin{array}{c}\text { Sai lệch } \\
\text { chuẩn }\end{array}$ & $\begin{array}{c}\text { Giá trị } \\
\text { tới hạn }\end{array}$ & P_value \\
\hline THÁI ĐỘ & $<---$ & LỘI ÍCH & 0,190 & 0,068 & 2,802 & 0,005 \\
\hline THÁI ĐỘ & $<---$ & RƯI RO & 0,022 & 0,067 & 0,330 & 0,741 \\
\hline MỨC ĐỘ & $<---$ & THÁI ĐỘ & 1,119 & 0,179 & 6,266 & 0,000 \\
\hline MỨC ĐỘ & $<---$ & LỘI ÍCH & 0,001 & 0,027 & 0,051 & 0,960 \\
\hline MỨC ĐỘ & $<---$ & RƯI RO & $-0,074$ & 0,025 & $-2,969$ & 0,003 \\
\hline MỨC ĐỘ & $<---$ & QUAN HỆ & 0,049 & 0,027 & 1,825 & 0,068 \\
\hline MỨC ĐỘ & $<---$ & CUNG ỨNG & $-0,036$ & 0,031 & $-1,177$ & 0,239 \\
\hline MỨC ĐỘ & $<---$ & CHIÊN LỰ̛C & 0,031 & 0,042 & 0,726 & 0,468 \\
\hline MỨC ĐỘ & $<---$ & CHỨC NÂNG & 0,038 & 0,027 & 1,428 & 0,153 \\
\hline TÀI CHÍNH & $<---$ & MÚC ĐỘ & 0,250 & 0,097 & 2,568 & 0,010 \\
\hline
\end{tabular}

Nguồn: Kết quả xử lý từ số liệu điều tra 153 doanh nghiệp

Tuy nhiên, kết quả Bảng 6 cho thấy ở độ tin cậy $95 \%$ thì nghiên cứu chưa tìm thấy sự tác động của: (1) yếu tố rủi ro đến thái độ thuê ngoài; (2) yếu tố lợi ích, định hướng chiến lược, đặc điểm chức năng và yếu tố nhà cung ứng đến mức độ thuê ngoài. Do đó tác giả tiến hành phân tích SEM lần 2 (Hình 4). 


\section{Chi-square $=309.511 ; \mathrm{df}=178 ; \mathrm{P}=.000$ \\ Chi-square/df $=1.739$ \\ $\mathrm{TLI}=.901 ; \mathrm{CFI}=.916$ \\ RMSEA $=.070$}

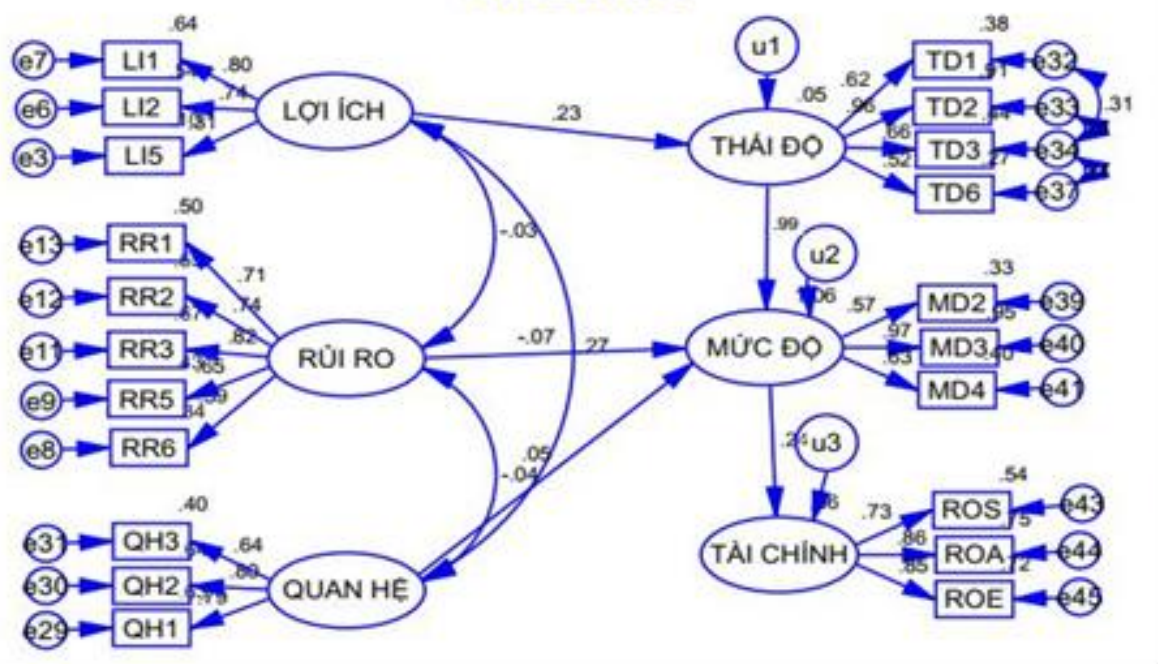

Hình 4. Kết quả phân tích SEM điều chỉnh

Nguồn: Kết quả xử lý từ số liệu điều tra 153 doanh nghiệp

\section{Bảng 7}

Các trọng số đã chuẩn hóa trong mô hình SEM điều chỉnh

\begin{tabular}{|l|c|l|c|c|}
\hline \multicolumn{3}{|c|}{ Mối quan hệ } & Hệ số tương quan & P_value \\
\hline THÁI ĐỘ & $<---$ & LợI ÍCH & 0,233 & 0,018 \\
\hline MỨC ĐỘ & $<---$ & THÁI ĐỘ & 0,992 & 0,000 \\
\hline MỨC ĐỘ & $<---$ & RỦI RO & $-0,072$ & 0,008 \\
\hline MỨC ĐỘ & $<---$ & QUAN HỆ & 0,055 & 0,037 \\
\hline HIỆU QUẢ & $<---$ & MỨC ĐỘ & 0,236 & 0,010 \\
\hline
\end{tabular}

Nguồn: Kết quả xử lý từ số liệu điều tra 153 doanh nghiệp

Kết quả Bảng 7 cho thấy, việc sử dụng các nguồn lực thuê ngoài của các DNNVV ở TP. Cần Thơ phụ thuộc vào 3 yếu tố: (1) yếu tố nhận thức rủi ro từ hoạt động thuê ngoài đối với doanh nghiệp, (2) thái độ của doanh nghiệp đối với hoạt động thuê ngoài và (3) yếu tố mối quan hệ giữa các bên liên quan. Trong đó, yếu tố thái độ của doanh nghiệp tác động đáng kể và mạnh nhất đến việc thuê ngoài. Kết quả Bảng 7 cũng cho thấy được, thuê ngoài dịch vụ của các DNNVV ở TP. Cần Thơ đã đem lại hiệu quả tài chính doanh nghiệp. Kết quả Hình 4 cho thấy, việc thuê ngoài giúp doanh nghiệp cải thiện đáng kể hiệu quả tỷ suất lợi nhuận trên tài sản (ROA) và tỷ suất lợi nhuận trên vốn chủ sở hữu(ROE). Bên cạnh đó, thông qua thuê ngoài, các DNNVV ở TP. Cần Thơ còn đạt được hiệu quả tỷ suất lợi nhuận trên doanh thu (ROS). Điều này là hoàn toàn phù hợp với giả thuyết cho rằng thuê ngoài dịch vụ có sự tác động tích cực đến hiệu quả tài chính doanh nghiệp. 


\section{Kết luận và hàm ý nghiên cứu}

\subsection{Kết luận}

Như vậy, qua kết quả nghiên cứu cho thấy, thuê ngoài dịch vụ có sự tác động tích cực đến các chỉ tiêu đánh giá hiệu quả tài chính (tác động đến tỷ suất ROS, ROA và ROE) của các DNNVV ở TP. Cần Thơ. Trong đó, tác động mạnh nhất đến tỷ suất ROA và ROE. Mặc dù, các loại dịch vụ được các doanh nghiệp sử dụng rất đa dạng và khác nhau, nhưng việc thuê ngoài của doanh nghiệp phụ thuộc 3 yếu tố cơ bản bao gồm: (1) nhận thức rủi ro từ thuê ngoài, (2) thái độ thuê ngoài và (3) yếu tố mối quan hệ trong thuê ngoài. Như vậy, khác so với các nghiên cứu trước đây, nghiên cứu này đã dựa trên lý thuyết mối quan hệ RT của Klepper (1995) và đã phát hiện được sự ảnh hưởng của yếu tố mối quan hệ giữa các bên trong việc đi thuê đến việc thuê ngoài của doanh nghiệp. Bởi lẽ, kết quả nghiên cứu cho thấy, thuê ngoài dịch vụ đối với các DNNVV ở TP. Cần Thơ cũng chứa đựng yếu tố rủi ro (Phụ thuộc nhà cung ứng, mất khả năng kiểm soát, gián đoạn quá trình thực hiện công việc, chi phí có thể tăng và nguy co bị lộ bí mật, thông tin doanh nghiệp). Do đó, để hạn chế những rủi ro thì doanh nghiệp thuê ngoài chú ý yếu tố mối quan hệ quen biết với bên cung ứng tại địa phương để xây dựng quan hệ trong dài hạn.

\subsection{Hàm ý quản trị}

Kết quả nghiên cứu cho thấy, mặc dù thuê ngoài dịch vụ đã mang lại hiệu quả hoạt động cho DNNVV ở TP. Cần Thơ. Nhưng hoạt động này, vẫn tiềm ẩn những rủi ro như đã trình bày ở phần trên. Do đó, để nâng cao hiệu quả hoạt động thuê ngoài các doanh nghiệp cần hạn chế sự lệ thuộc quá nhiều vào bên cung ứng bằng các điều khoản chặt chẽ trong hợp đồng thuê ngoài. Tăng cường hoạt động kiểm soát hoạt động, kiểm tra kế hoạch thực hiện bên cung ứng nhằm hạn chế tình trạng gián đoạn công việc tại doanh nghiệp. Ngoài ra, để tránh trường hợp chi phí phát sinh đòi hỏi doanh nghiệp phải nghiên cứu dự toán đầy đủ các khoản chi phí. Và đặc biệt, việc thuê ngoài có thể dẫn đến nguy cơ lộ bí quyết, thông tin doanh nghiệp. Do đó, doanh nghiệp cần xác định rõ, chỉ thuê ngoài những hoạt động không quan trọng, không mang tính cốt lõi. Bên cạnh đó, để nâng cao hiệu quả thuê ngoài các doanh nghiệp cần tăng cường nghiên cứu, thu thập các thông tin liên quan đến hoạt động này, có thể nhờ đến sự tư vấn, hỗ trợ của đội ngũ chuyên gia, qua đó doanh nghiệp có thể nhận thức được một cách đầy đủ và chính xác hơn các yếu tố ảnh hưởng đến việc thuê ngoài dịch vụ.

Hạn chế của đề tài và đề xuất hướng nghiên cứu: (1) đáp viên trả lời bảng khảo sát có thể là người không nắm rõ đầy đủ các thông tin liên quan đến nghiên cứu này; (2) các yếu tố ảnh hưởng đến thuê ngoài được đo lường thông qua cảm nhận của đáp viên nên có thể tính chủ quan sẽ cao, do đó có thể không đánh giá chính xác thực tế các yếu tố tác động đến việc thuê ngoài; (3) thang đo hiệu quả tài chính của doanh nghiệp trong nghiên cứu được đo lường thông qua cảm nhận của đáp viên chứ không dựa trên số liệu thực tế do tính bảo mật thông tin doanh nghiệp. Bên cạnh đó, do hạn chế về thời gian và kinh phí cũng như khó khăn trong việc tiếp cận các đối tượng điều tra là những nhà quản trị cấp cao, thủ trưởng các phòng ban chức năng liên quan đến hoạt động thuê ngoài, nên nghiên cứu còn hạn chế về cỡ mẫu cũng như tiếp cận doanh nghiệp có qui mô lớn hơn. Do đó, các nghiên cứu tiếp theo có thể mở rộng nghiên cứu cả doanh nghiệp có qui mô lớn với cỡ mẫu nhiều hơn. 


\section{Tài liệu tham khảo}

Anders, I., \& Björn, L. (2015). Outsourcing strategies and their impact on financial performance in small manufacturing firms in Sweden. International Journal of Business and Finance Research, 9(4), 11-20.

Aron, R., \& Singh, J. (2005). Getting offshoring right. Harvard Business Review, 83(12), 13543.

Azurin, S., Shahin, D., \& Sulaiman, A. (2013). Outsourcing patterns among Malaysian hotels. International Journal of Business and Social Science, 4(9), 133-144.

Bustinza, O., Arias-Aranda, D., Gutierrez-Gutierrez, L. (2010). Outsourcing, competitive capabilities and performance: An empirical study in service firms. International Journal of Production Economics, 126(2), 276-288.

Coase, R. H. (1937). The nature of the firm. Economica, 6(16), 331-351.

Dinh, T. C., \& Le, N. T. (2017). Phân tích sự tác động của lợi ích - rủi ro đến thái độ và mức độ sử dụng dịch vụ thuê ngoài của các doanh nghiệp tại thành phố Cần Thơ [Analyzing the impact of benefits and risks on the attitude and level of using outsourcing services of enterprises in Can Tho city]. Tap chí Khoa hoc Đại hoc Mở TP.HCM, 52(1), 93-104.

Dong, H., Seongcheol, K., Changi, N., \& Ja, W. (2007). Developing a decision model for business process outsourcing. Computers \& Operations Research, 34(12), 3769-3778.

Fornell, C., \& Larcker, D. F. (1981). Evaluating structural equation models with unobservable. Journal of Marketing Research, 18(1), 39-50.

Gerald, A. S., Grace, M., \& Christina, A. (2013). Outsourcing in cooperatives in Tanzania: Assessing the contribution of outsourcing on organisational performance. European Journal of Business and Management, 5(15), 99-104.

Gewald, H. (2010). The perceived benefits of business process outsourcing: An empirical study of the German banking industry. Strategic Outsourcing: An International Journal, 3(2), 89-105.

Gewald, H., \& Dibbern, J. (2009). Risks and benefits of business process outsourcing: A study of transaction services in the German banking industry. Information \& Management, 46(4), 249-257.

Gilley, K. M., Greer, R., \& Rasheed, A. (2004). Human resource outsourcing and organizational performance in manufacturing firms. Journal of Business Research, 57(3), 232-240.

Hafeez, A., \& Andersen, O. (2014). Factors influencing accounting outsourcing practices among SMEs in Pakistan context: Transaction cost economics (TCE) and resource-based views (RBV) prospective. International Journal of Business and Management, 9(7), 1932.

Hair, J. F., Anderson, R. E., Tatham, R. L., \& Black, W. C. (1998). Multivariate data analysis (5th ed). Upper Seddle River, NJ: Prentice-Hall International.

Hirotoshi, K. (2013). Production outsourcing and firm performance: An empirical analysis of Japanese manufacturers. Journal of Business Studies Quarterly, 5(1), 1-13. 
Hoyle, R. H. (1995). Structural equation modeling: Concepts, issues, and applications. Thousand Oaks, CA: Sage Publications.

Kaplan, R. S., \& Norton, D. P. (1992). In search of excellence-der Maßstab muß neu definiert werden. Harvard Manager, 14(4), 37-46.

Klepper, R. (1995). The management of partnering development in IS outsourcing. Journal of Information Technology, 10(4), 248-258.

Kroes, J. R., \& Ghosh, S. (2010). Outsourcing congruence with competitive priorities: Impact on supply chain and firm performance. Journal of Operations Management, 28(2), 124143.

Kwok, H. L., \& Jianmei, Z. (2006). Driversand obstacles of outsourcing practices in China. International Journal of Physical Distribution and Logistics Management, 36(10), 776-792.

Marr, B. (2005). Business performance measurement: An overview of the current state of use in the USA. Measuring Business Excellence, 9(3), 55-56.

Nguyen, T. D., \& Nguyen, T. M. T. (2008). Nghiên cúu khoa hoc marketing - Úng dụng mô hình cấu trúc tuyến tính SEM. Ho Chi Minh, Vietnam: Đại học Quốc gia TP.HCM.

Ondoro, C. O. (2015). Measuring organization performance from balanced scorecard to balanced ESG framework. International Journal of Economics, Commerce and Management, 11(3), 715-725.

Prahalad, C. K., \& Hamel, G. (1990). The core competence of the corporation. Harvard Business Review, 68(3), 79-91.

Richard, P. J., Devinney, T. M., Yip, G. S., \& Johnson, G. (2009). Measuring organizational performance: Towards methodological best practice. Journal of Management, 35(3), 718804.

Williamson, O. E. (1975). Markets and hierarchies: Analysis and antitrust implications. New York, NY: Free Press. 